\title{
Biodiversity mediates productivity through different mechanisms at adjacent trophic levels
}

\author{
ZT Long \\ Virginia Institute of Marine Science \\ JF Bruno \\ JE Duffy \\ Virginia Institute of Marine Science
}

Follow this and additional works at: https://scholarworks.wm.edu/vimsarticles

Part of the Biodiversity Commons

\section{Recommended Citation}

Long, ZT; Bruno, JF; and Duffy, JE, Biodiversity mediates productivity through different mechanisms at adjacent trophic levels (2007). Ecology, 88(11), 2821-2829.

10.1890/06-1977.1

This Article is brought to you for free and open access by the Virginia Institute of Marine Science at W\&M ScholarWorks. It has been accepted for inclusion in VIMS Articles by an authorized administrator of W\&M ScholarWorks. For more information, please contact scholarworks@wm.edu. 


\title{
BIODIVERSITY MEDIATES PRODUCTIVITY THROUGH DIFFERENT MECHANISMS AT ADJACENT TROPHIC LEVELS
}

\author{
Zachary T. Long, ${ }^{1,2,4}$ John F. Bruno, ${ }^{3}$ and J. Emmett Duffy ${ }^{2}$ \\ ${ }^{1}$ Institute of Marine Sciences, The University of North Carolina, Chapel Hill, Morehead City, North Carolina 28557 USA \\ ${ }^{2}$ School of Marine Sciences, The College of William and Mary, Gloucester Point, Virginia 23062-1346 USA \\ ${ }^{3}$ Department of Marine Sciences, The University of North Carolina at Chapel Hill, Chapel Hill, North Carolina 27599-3300 USA
}

\begin{abstract}
Biodiversity may enhance productivity either because diverse communities more often contain productive species (selection effects) or because they show greater complementarity in resource use. Our understanding of how these effects influence community production comes almost entirely from studies of plants. To test whether previous results apply to higher trophic levels, we first used simulations to derive expected contributions of selection and complementarity to production in competitive assemblages defined by either neutral interactions, dominance, or a trade-off between growth and competitive ability. The three types of simulated assemblages exhibited distinct interaction signatures when diversity effects were partitioned into selection and complementarity components. We then compared these signatures to those of experimental marine communities. Diversity influenced production in fundamentally different ways in assemblages of macroalgae, characterized by growthcompetition trade-offs, vs. in herbivores, characterized by dominance. Forecasting the effects of changing biodiversity in multitrophic ecosystems will require recognizing that the mechanism by which diversity influences functioning can vary among trophic levels in the same food web.
\end{abstract}

Key words: biodiversity; complementarity effect; ecosystem functioning; food web; selection effect; tripartite partition.

\section{INTRODUCTION}

The potential influence of changing biodiversity on ecosystem functioning has received much attention (Naeem et al. 1994, Huston 1997, Loreau and Hector 2001, Loreau et al. 2001, Tilman et al. 2001, Downing and Leibold 2002, Thebault and Loreau 2003, Hooper and Dukes 2004, Bell et al. 2005, Downing 2005, Hooper et al. 2005, Wardle and Zackrisson 2005). One of the principal generalizations emerging from this growing body of evidence is that diverse communities are often more productive than depauperate ones (Hooper et al. 2005). Most of these studies, however, considered only primary producers (Huston 1997, Loreau and Hector 2001, Loreau et al. 2001, Tilman et al. 2001, Hooper and Dukes 2004, Hooper et al. 2005, Wardle and Zackrisson 2005) and the results from the relatively small number of studies that have investigated other trophic levels are variable (e.g., Norberg 2000, Downing and Leibold 2002, Cardinale et al. 2003, Duffy et al. 2003, 2005, Finke and Denno 2004, Downing 2005, Gamfeldt et al. 2005, Byrnes et al. 2006). Yet, all natural communities consist of multiple trophic levels and reductions of

Manuscript received 28 November 2006; revised 6 March 2007; accepted 21 March 2007. Corresponding Editor: J. J. Stachowicz.

${ }^{4}$ Present address: McGill University, Department of Biology, 1205 Rue Doctor Penfield, Montreal, Quebec H3A 1B1 Canada. E-mail: zachary.long@mcgill.ca biodiversity in nature generally occur at higher trophic levels (Duffy 2003, Petchey et al. 2004). Thus, a pressing question is whether the paradigm for functional consequences of biodiversity loss derived from studies of competitive plant assemblages can be extrapolated to complex, multi-trophic-level systems (Loreau et al. 2001, Duffy 2002, Thebault and Loreau 2003, Hooper et al. 2005, Ives et al. 2005).

Aggregate productivity of a diverse community depends both on which species are present and on their interactions, including competition, differential resource use, and facilitation. Directly assessing the importance of these mechanisms in a community requires numerous painstaking experiments that are logistically prohibitive or impossible. Therefore, indirect methods have been developed to estimate relative importance of competitive dominance vs. "complementarity," a composite measure of differential resource use and interspecific facilitation, in contributing to the aggregate production of multispecies assemblages. The foundation of this approach was Loreau and Hector's (2001) method for partitioning the net biodiversity effect on the yield of a multi-species assemblage. The net biodiversity effect is measured as the difference between the observed total yield and the expected total yield of a mixture under the null hypothesis of identical intra- and interspecific interactions. The observed total yield of a mixture is simply the sum of observed yields of all species in that mixture. The expected total yield is the sum of the expected yields of 
each species present in that mixture, which are calculated as the product of a species' expected relative yield (the proportion in which it is seeded or planted, $\mathrm{RY}_{\mathrm{E}}$ below) and its yield in monoculture. In an extension of this approach, Fox (2005) defined a tripartite partition that separates the net biodiversity effect into three components with clear biological implications. These are traitindependent complementarity (TIC), trait-dependent complementarity (TDC), and the dominance effect (DE). Fox's (2005) tripartite partition can be written as

$$
\begin{aligned}
\Delta Y= & N \overline{\Delta \mathrm{RY}} \times \bar{M}+N \operatorname{cov}\left(M, \mathrm{RY}_{\mathrm{O}}-\frac{\mathrm{RY}_{\mathrm{O}}}{\mathrm{RYT}_{\mathrm{O}}}\right) \\
& +N \operatorname{cov}\left(M, \frac{\mathrm{RY}_{\mathrm{O}}}{\mathrm{RYT}_{\mathrm{O}}}-\mathrm{RY}_{\mathrm{E}}\right)
\end{aligned}
$$

where the first product on the right hand side of the equation quantifies the contribution of TIC, the first covariance term quantifies the contribution of TDC, and the final term quantifies the contribution of DE to the net biodiversity effect. Here, $\Delta Y$ is the net biodiversity effect, $N$ is the number of species present in the mixture, $\bar{M}$ is the average mass of all species in monoculture, and $\overline{\Delta R Y}$ is the average deviation between observed $\left(\mathrm{RY}_{\mathrm{O}}\right)$ and expected $\left(R Y_{E}\right)$ relative yields of all species present in the mixture. $\mathrm{RY}_{\mathrm{O}}$ of a species is calculated as its mass in mixture divided by its mass in monoculture. $R Y_{E}$ of a species is the proportion in which a species is seeded or planted in mixture. $\mathrm{RYT}_{\mathrm{O}}$ is the sum of $\mathrm{RY}_{\mathrm{O}}$ for all species in the mixture.

The first two components (TIC and TDC) of the tripartite partition reflect niche partitioning (differential resource use) among species, and greater positive values indicate a higher total yield in mixture relative to additive predictions based on monoculture yields. The three components of Fox's tripartite partition are related to the additive partition of Loreau and Hector (2001). The sum of the two covariance terms (TDC and DE) is identical to the selection effect of Loreau and Hector (2001). TIC is identical to the complementarity effect of Loreau and Hector (2001) and has been used previously to quantify the effect of diversity per se (i.e., due to species interactions), on ecosystem production. TIC quantifies the deviation between observed and expected yield that are independent of species traits (here, yield in monoculture). A positive TIC indicates that the observed total yield in mixture exceeds that expected from monoculture performances, the increase in yield of one species does not decrease the average yield of others in mixture, and the best performers in mixture are not predictable from their monoculture yields. This occurs, for example, when species occupy distinct niches or interact positively via facilitation. TIC will be negative when the observed relative yields in mixture are, on average, less than relative yields expected $\left(\mathrm{RY}_{\mathrm{O}}<\mathrm{RY} \mathrm{Y}_{\mathrm{E}}\right.$, on average). Negative TIC can occur due to physical or chemical interference among species (Loreau and Hector 2001).
TDC also quantifies the departure of mixture yield from the expected production based on monoculture yields. In contrast to TIC, TDC quantifies the extent to which species' changes in relative yield are nonrandomly associated with their traits (here, yield in monoculture). Fox (2005) has interpreted positive TDC as reflecting nested niches, that is, "one-way" complementarity where one species benefits from growing in the presence of another, but the effect is not reciprocated (Fox 2005). TDC is positive when species with high yield in monoculture achieve a higher than expected relative yield in mixture, but do not reduce the average relative yield of the smaller species. This commensalism may occur, for instance, if the strength of intraspecific competition experienced by two species of different sizes exceeds that of interspecific competition, and the niche of the larger species entirely overlaps that of the smaller species. Thus, in monoculture individuals of both species compete intraspecifically over their entire niche, but in mixture individuals of the larger species experience a release from intraspecific competition where its niche is not occupied by the smaller species (Murrell and Law 2003). Conversely, TDC can be negative when species with low yield in monoculture attain high relative yield in mixture, but not at the expense of other species. This may occur for instance, if the niche of a larger species encompasses the niche of a smaller species as above, and the smaller species is a better competitor than the larger species where their niches overlap. Thus, the smaller species experiences a competitive release in mixture and obtains a higher relative yield than expected (based on its monoculture yield), while the observed relative yield of the larger species does not differ from expectation because it can utilize niche space not available to the smaller species.

The final term, DE, reflects negative interactions among species, usually considered to result from resource competition. Positive values of DE occur when species with high yield in monoculture also achieve high yield in mixture at the expense of other species. Negative values of DE occur when species with low monoculture yields dominate mixtures at the expense of other species. DE differs from TDC because DE quantifies the extent to which increases in productivity in mixture relative to monoculture come at the expense of other species.

A key insight of previous work that examined diversity effects using the partitioning approach is that the different components can simultaneously influence the net biodiversity effect (Loreau and Hector 2001, Bruno et al. 2005, 2006). In this paper, we use simulation modeling to investigate how different types of species interactions produce differences in total community biomass yield, and how those differences are reflected in the components of the partitioned biodiversity effect. By plotting pair-wise correlations between components of the net biodiversity effect (TIC, TDC, DE) in simulated communities, we developed a graphical "interaction signature" that reflects the predominant mode of 
interaction mediating diversity effects on production. We then compared the interaction signatures of different simulated communities to those calculated from a series of experiments to test whether the species interactions mediating diversity effects on production differed among trophic levels in real communities.

\section{Methods}

\section{Simulations}

We first used numerical simulations to derive expected contributions of the three components of the tripartite partition in affecting production in mixed-species assemblages. We simulated three types of competitive assemblages defined by different relationships between a species' yield in monoculture and its competitive ability (measured as its yield in mixture). In "neutral" communities, yield of a species in mixture is approximately proportional to its yield in monoculture. In "dominant" communities, species that attain higher monoculture yields perform better than expected, on average, in mixture at the expense of species that attain lower monoculture yields. This simulates the sampling effect that Huston (1997) suggested may explain the higher production of diverse plant assemblages observed in early experiments manipulating plant diversity. Conversely, in "trade-off" communities, species that attain lower yields in monoculture perform better than expected, on average, in mixture at the expense of species that attain higher yields in monoculture. Tradeoff communities simulate the trade-off between growth and competitive ability commonly seen in plant succession (Grime 2001, Rees et al. 2001).

Calculating the components of Fox's (2005) tripartite partition requires comparisons between yield of a species in monoculture and its yield in mixture. Our simulations varied how a species yield in mixture was calculated to reflect differences in the dominant mode of species interaction and to generate the "neutral," "dominant," or "trade-off" communities. Additionally, we determined monoculture and mixture yields for each community at three levels of diversity (five, 10 , or 20 species) to investigate the influence of richness on TIC, TDC, and DE. Our simulations began by setting a species yield in monoculture as a random number between one and 100. For "neutral" communities, yield in mixture was calculated as monoculture yield divided by a random number between $N \pm N / 5$, where $N$ is species richness. Dividing by a random number introduced stochasticity into the calculation of relative yield. Thus, across species, yield in mixture was approximately proportional to yield in monoculture. In the absence of stochasticity, the relative yield of a species in mixture would exactly equal the expected yield and the values of each component would be zero. Introducing stochasticity as $\pm N / 5$ allowed the variation to increase proportionally with species richness $( \pm 1, \pm 2, \pm 4$ for $N=5, N=10, N=$ 20 , respectively). For example, the yield of species A in mixture was calculated as follows:
Yield of species A in monoculture $\overline{\text { Random number between }(N \pm N / 5)}$.

In "dominant" communities, the yield of a species A in mixture was calculated as

$$
\begin{aligned}
& \frac{\text { Yield of species A in monoculture }}{\text { Average monoculture yield }} \\
& \quad \times \frac{\text { Yield of species A in monoculture }}{\text { Random number between }(N \pm N / 5)} .
\end{aligned}
$$

The second term is identical to mixture yield for "neutral" communities. The first term provides an additional increase in yield for species that perform better than the average monoculture and a penalty for species that perform worse than the average monoculture.

Finally, in "trade-off" communities, species yield in mixture was calculated as

$$
\begin{aligned}
& \frac{\text { Average monoculture yield }}{\text { Yield of species A in monoculture }} \\
& \quad \times \frac{\text { Yield of species } \mathrm{A} \text { in monoculture }}{\text { Random number between }(N \pm N / 5)} .
\end{aligned}
$$

Here, the first term provides a penalty for species that perform better than the average monoculture, and an increase in yield for species that perform worse than the average monoculture.

Generating monoculture and mixture yields as above offered several advantages. First, our method allowed us to maintain a gradient in diversity. Using dynamic models or Lotka-Volterra models would have only allowed us to control for initial diversity. Final diversity in mixtures would have varied depending on interaction strengths, and may not have conserved our desired gradient in diversity. Additionally, dynamic and LotkaVolterra models may have generated cyclic dynamics or nonequilibrium outcomes. We recognize that there are advantages to using a dynamic model, and are currently using dynamic models in a manner similar to the approach described here to address similar questions. Second, our method allowed for transgressive overyielding (mixture yield exceeds the maximum monoculture yield), non-transgressive overyielding (mixture yield exceeds the average monoculture yield, but not the maximum monoculture yield), and underyielding (mixture yield is less than the average monoculture yield; Fridley 2001).

A single replicate of the simulation consisted of calculating monoculture and mixture yields separately for one replicate "plot" at each of the three levels of diversity. We then used the simulated monoculture and mixture yields to calculate TIC, TDC, and DE for each replicate, again separately for the three levels of diversity. Thus, we obtained three estimates of the components in each replicate, one each for the three levels of richness (five, 10, and 20 species). Different 
levels of richness used different species, meaning that the five species used in the lowest level of richness were not duplicated in either of the higher levels of species richness, and the 10 species used in our medium level of richness were not duplicated in the communities with 20 species. Using different compositions in each diversity level allowed each replicate to be statistically independent. Alternatively, we could have created the different levels of richness by drawing from the same species pool, i.e., species in the lower levels of richness would consist of subsets of the species in the higher levels of richness. We did not use this method to avoid problems with confounding composition and diversity (Fukami et al. 2001). One run of the simulation consisted of calculating 10 replicates for each level of richness, and thus producing 30 total estimates of each component (10 runs by three richness levels). We used Pearson's correlation coefficients to test for pairwise relationships among the three components of the net biodiversity effect in each run of the simulation $(N=30)$. The values of TIC, TDC, and DE were normally distributed (see Fig. 1 for representative data from one run). We conducted 100 runs of the simulation separately for each type of community (neutral, dominance, and tradeoff) and calculated Pearson's correlation coefficients for each run. This resulted in 300 total correlations for each type of community (three pairwise correlations by 100 runs). We investigated whether there were consistent relationships among components, or "interaction signatures," in each type of community by plotting the three pairwise correlations within a run, and also by tabulating the number of significant relationships (and their sign) across all 100 runs of the simulation.

\section{Experiments}

We compared the results from simulations with results from eight experiments that manipulated diversity of marine macroalgae or herbivores and measured biomass accumulation. The eight experiments (Duffy et al. 2001, 2003, 2005, Bruno et al. 2005) each employed a substitutive design as assumed by Loreau and Hector (2001) and Fox (2005) and therefore included replicated mixtures of different levels of diversity and replicated monocultures of each species present in the mixture (Table 1). The experiments testing for biodiversity effects on macroalgal biomass yield were measured in three field and two mesocosm experiments that included up to nine algal species but excluded animals (Bruno et al. 2005). The experiments testing effects of herbivore (amphipod and isopod crustacean) diversity on herbivore density included up to six species (Duffy et al. 2001, 2003, 2005). For each experiment, we calculated the average yield in replicated monocultures for each species. We then used the average monoculture yields and the yields of each species in mixture to calculate TIC, TDC, and DE components for each replicated mixture according to Fox (2005). This resulted in calculating 85 estimates of each component in the macroalgal studies and 21 estimates of each component in the herbivore studies (Table 1). We calculated Pearson's correlation coefficients among the three pairs of components separately for macroalgal and herbivore communities, and compared the sign and magnitude of the relationships found in the experiments to the relationships obtained with the simulations.

\section{RESUlts}

Our numerical simulations demonstrated that the way in which species interact affects the magnitude and sign of the components of the tripartite partition (Fig. 1). In neutral communities the three components were relatively constrained around zero (Fig. 1A, D, G). In dominant communities, values of TIC and TDC were also relatively constrained around zero (Fig. 1E). Values of $\mathrm{DE}$, however, showed a large positive range $(0<\mathrm{DE}$ $<\approx 30$, Fig. $1 \mathrm{H}$ ). In trade-off communities, the ranges of TDC and DE were large and negative $(\approx-40<\mathrm{DE}<$ 0 , and $\approx-200<$ TDC $<0$, Fig. 1I) and the range of TIC was large and positive $(0<$ TIC $<\approx 250$, Fig. 1C, F). Additionally, the simulations demonstrated that the way in which species interact dramatically affects the strength and sign of relationships among the three components of the net biodiversity effect, producing a distinct interaction signature (Figs. 1A-I and 2A). In neutral communities, TDC and DE generally were positively correlated, whereas there was no consistent relationship among the other components (Fig. 2A). Conversely, in dominant communities, TIC and TDC were strongly positively correlated, with no consistent relationship among other components (Fig. 2A). Finally, in trade-off communities, TIC was strongly negatively correlated with both TDC and DE, whereas TDC and DE were strongly positively correlated (Fig. 2A).

The interaction signature for experimental macroalgal assemblages was remarkably similar to that produced by the simulated trade-off communities; specifically, TIC was strongly negatively related to both TDC and DE components, whereas TDC and DE were strongly positively related (Figs. 2B and 3A, C, E). In contrast, the interaction signature for experimental herbivore assemblages was qualitatively similar to that of the simulated dominant communities (Figs. 2B and $3 \mathrm{~B}, \mathrm{D}, \mathrm{F}$ ) in that only TIC and TDC were (positively) correlated. Experiments and simulations were also consistent in that herbivore diversity enhanced secondary production (herbivore yield) in both simulated dominant communities (Fig. 1N) and in experiments (Duffy et al. 2003, 2005), whereas algal diversity rarely enhanced algal biomass yield in either simulated tradeoff communities (Fig. 1O) or in experiments (Bruno et al. 2005).

\section{Discussion}

Our simulation results suggest that species interactions can not only influence the magnitudes and signs of the three components of the net biodiversity effect (TIC, 

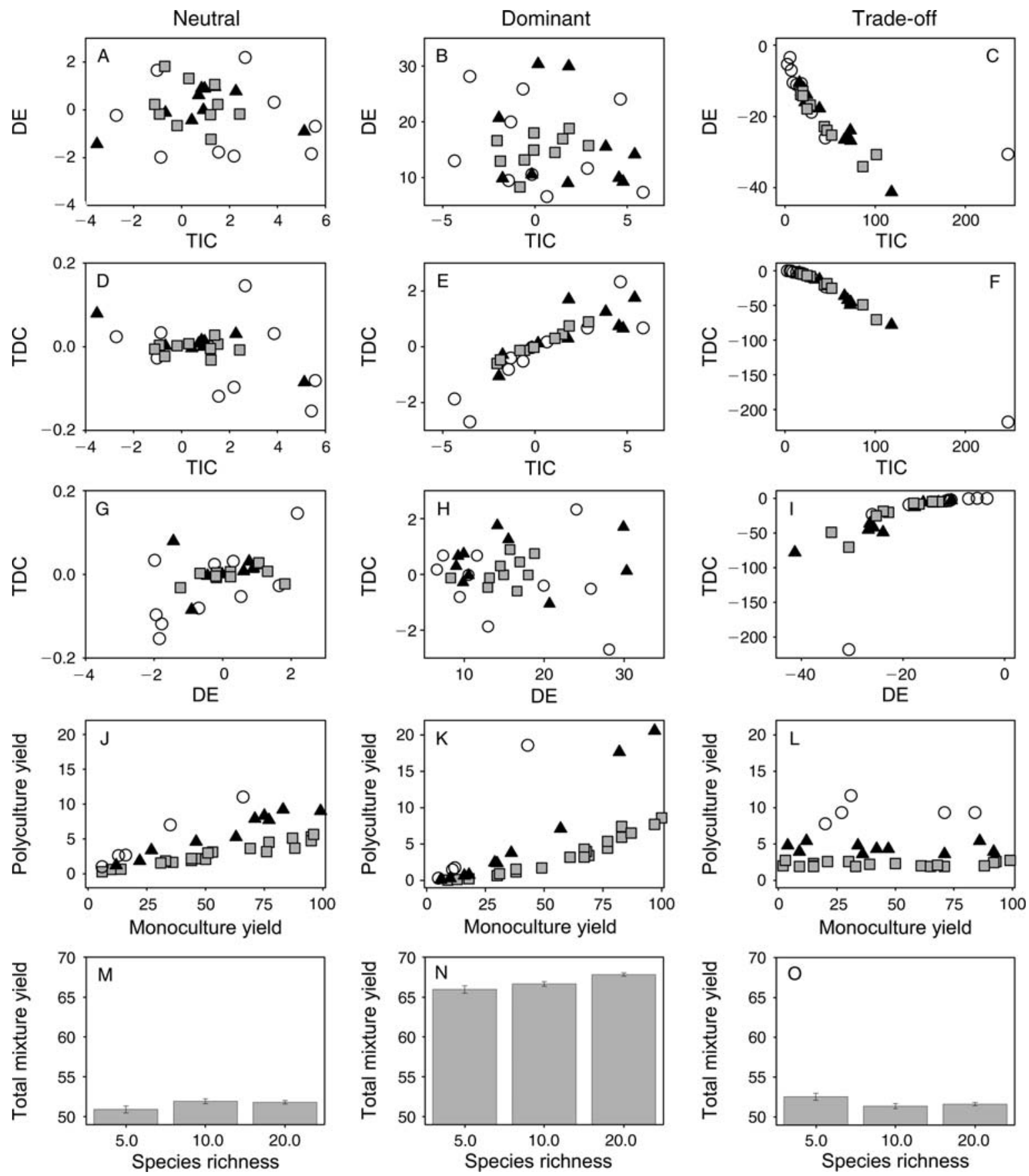

FIG. 1. Representative simulation results from each of the three community types. Open circles, triangles, and squares represent replicate communities with 5, 10, and 20 species, respectively. Panels A-I show relationships between the three pairs of biodiversity components in one simulation run; one run includes 30 replicate communities ( 10 communities per diversity level). The biodiversity components are trait-independent complementarity (TIC), trait-dependent complementarity (TDC), and the dominance effect (DE). Panels J-L show the relationships between monoculture and mixture yields from one replicate; one replicate includes 35 species $(5+10+20$ species). Panels $\mathrm{M}-\mathrm{O}$ show yield (mean $\pm \mathrm{SE})$ in the three diversity levels within each community type over all simulations $(N=100$ simulations $)$.

TDC, DE), but can also influence relationships among the three components. Plotting pair-wise correlations between the three components produced a graphical "interaction signature" that reflects the predominant mode of interaction mediating diversity effects on biomass production. Comparing these interaction signatures to those observed in the experiments suggests that the mechanisms by which species interact to 
TABLE 1. Specific design of each experiment used to calculate the three components of Fox's tripartite partition.

\begin{tabular}{|c|c|c|c|c|}
\hline System & $\begin{array}{l}\text { Trophic } \\
\text { level }\end{array}$ & Citation & Species utilized & $\begin{array}{l}\text { No. replicates of different } \\
\text { levels of diversity }\end{array}$ \\
\hline Mesocosm & macroalgae & Bruno et al. (2005) & $\begin{array}{l}\text { Agardhiella ramosissima, Codium fragile, } \\
\text { Enteromorpha linza, Gracilaria tikva- } \\
\text { hiae, Gracilaria verrucosa, Sargassum } \\
\text { filipendula, Ulva lactuca }\end{array}$ & $\begin{array}{l}10 \text { replicates of complete mixture of } \\
\text { seven species }\end{array}$ \\
\hline Mesocosm & macroalgae & Bruno et al. (2005) & $\begin{array}{l}\text { C. fragile, Dictyota menstrualis, Enetro- } \\
\text { morpha, G. tikvahiae, G. verrucosa, } \\
\text { Hypnea musciformis, Padina gymnos- } \\
\text { pora, S. filipendula, U. lactuca }\end{array}$ & $\begin{array}{l}10 \text { replicates of complete mixture of } \\
\text { nine species; } 10 \text { of random combi- } \\
\text { nations of six species; } 10 \text { of ran- } \\
\text { dom combinations of three species }\end{array}$ \\
\hline Mesocosm & macroalgae & Bruno et al. (2005) & $\begin{array}{l}\text { C. fragile, G. tikvahiae, } G \text {. verrucosa, } P \text {. } \\
\text { gymnospora, S. filipendula, U. lactuca }\end{array}$ & $\begin{array}{l}10 \text { replicates of complete mixture of } \\
\text { six species; } 10 \text { of random mixture } \\
\text { of three species }\end{array}$ \\
\hline Field & macroalgae & Bruno et al. (2005) & $\begin{array}{l}\text { C. fragile, D. menstrualis, G. tikvahiae, } \\
\text { H. musciformis, P. gymnospora, S. fili- } \\
\text { pendula }\end{array}$ & $\begin{array}{l}\text { eight replicates of complete mixture } \\
\text { of six species; } 10 \text { of random } \\
\text { mixture of three species }\end{array}$ \\
\hline Field & macroalgae & Bruno et al. (2005) & $\begin{array}{l}\text { C. fragile, G. tikvahiae, P. gymnospora, } \\
\text { S. filipendula }\end{array}$ & $\begin{array}{l}\text { seven replicates of complete mixture } \\
\text { of four species }\end{array}$ \\
\hline Mesocosm & herbivore & Duffy et al. (2001) & $\begin{array}{l}\text { Erichsonella attenuata, Gammarus } \\
\text { mucronatus, Idotea baltica }\end{array}$ & $\begin{array}{l}\text { six replicates of complete mixture of } \\
\text { three species }\end{array}$ \\
\hline Mesocosm & herbivore & Duffy et al. (2003) & $\begin{array}{l}\text { Bittium varium, Cymadusa compta, Duli- } \\
\text { chiella appendiculata, E. attenuata, } G \text {. } \\
\text { mucronatus, } I . \text { baltica }\end{array}$ & $\begin{array}{l}\text { five replicates of all six species; } \\
\text { five of random mix of three species }\end{array}$ \\
\hline Mesocosm & herbivore & Duffy et al. (2005) & $\begin{array}{l}\text { C. compta, E. attenuata, G. mucronatus, } \\
\text { I. baltica }\end{array}$ & five of complete mix of four species \\
\hline
\end{tabular}

Notes: Every species that was grown in the mixtures was also grown in monoculture. We used the average monoculture yield of each species (across all replicated monocultures within each experiment) and the yields of species in every replicated mixture to calculate the components of the partition. The mesocosm macroalgal studies were conducted at the Institute of Marine Science at the University of North Carolina at Chapel Hill, Morehead City, North Carolina, USA. The macroalgal field experiments were conducted near Morehead City and Beaufort, North Carolina, USA. The herbivore mesocosm studies were conducted at the Virginia Institute of Marine Sciences, Gloucester Point, Virginia, USA. See associated citations for additional details.

influence rates of biomass production differ among trophic levels in this subtidal marine food web. Previous theory anticipated that effects of diversity on production depend on species interactions, but concluded that biodiversity effects should be broadly similar in systems with one vs. two trophic levels (Ives et al. 2005). Our simulation results corroborate the predicted importance of species interactions in mediating biodiversity effects on yield. The experimental results suggest, however, that these interactions can differ between plant and herbivore trophic levels (Thebault and Loreau 2006). Our results are broadly consistent with those of Cardinale et al. (2006), who analyzed a larger sample of studies, in that both analyses found that species with high monoculture production also tended to dominate polycultures. Unlike Cardinale et al. (2006), however, we were able

\section{A) Simulations}

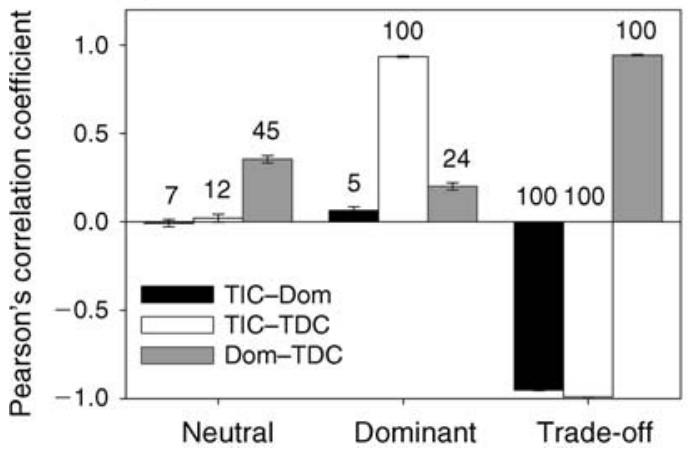

B) Experiments

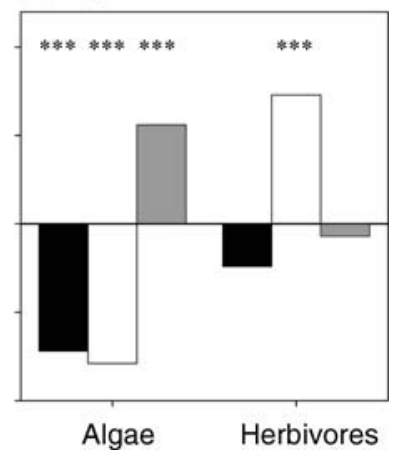

FIG. 2. Pearson's coefficients (mean $\pm \mathrm{SE}$ ) for correlations among the three pairs of biodiversity effect components for (A) the 100 simulations and for (B) the experiments. In both panels, different shaded bars indicate different pairs of components. The type of simulated community (neutral, dominant, or trade-off) in panel (A) and trophic level in panel (B) are indicated on the $x$-axis. In panel (A) the percentage of significant correlations among pairs of effects found in the simulations is indicated by the number above each bar $(P<0.05)$. Panel (B) shows the correlation coefficients from the three pairs of components obtained from the 85 estimates in algal experiments and the 21 estimates in the herbivore experiments. Asterisks above each bar in panel (B) indicate statistically significant correlations $(P<0.001)$. 

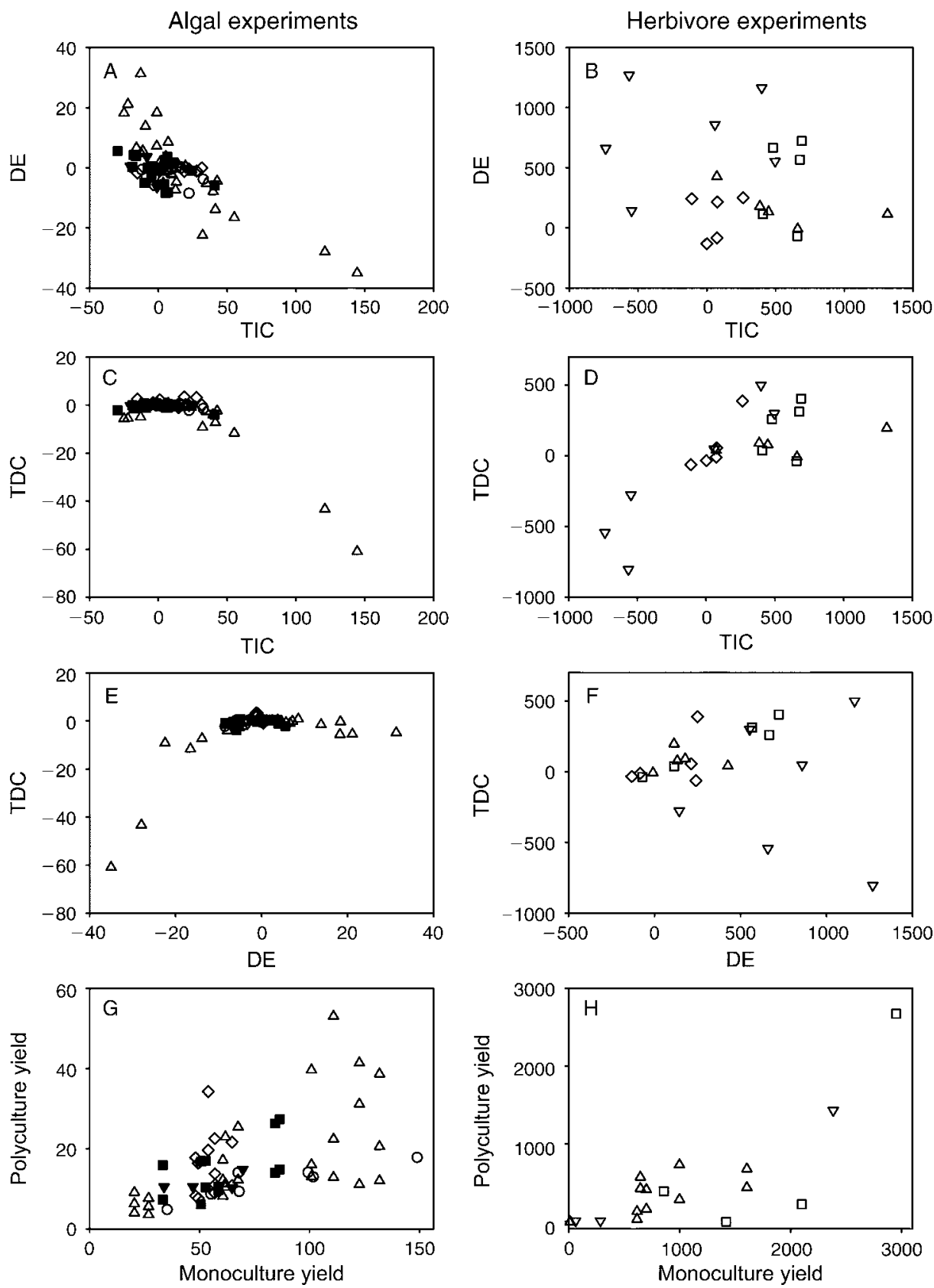

FIG. 3. Relationships between the three pairs of biodiversity effect partitions (panels A-F) and between the monoculture and mixture yields for experiments (panels $\mathrm{G}$ and $\mathrm{H}$ ) conducted on two different trophic levels. Different symbol shapes represent different experiments. Open and solid symbols represent replicates (for pairs of effects, panels A-F) or species (for mixture vs. monoculture yields, panels $\mathrm{G}$ and $\mathrm{H}$ ) from mesocosm and field experiments, respectively. The biodiversity components are traitindependent complementarity (TIC), trait-dependent complementarity (TDC), and the dominance effect (DE).

to explore mechanisms for these patterns by partitioning the diversity effect into components. This revealed that the superficially similar diversity effects at plant and herbivore levels were in fact produced by different mechanisms. This result has not previously been reported and would not have been detectable without partitioning the diversity effects. Moreover, the close match between the simulated and empirical patterns strengthens our conclusions that, in the system we studied, plant and herbivore diversity effects are mediated by different mechanisms.

In this system, several biological differences between sessile primary producers vs. mobile herbivores help to explain why biodiversity affects production differently 
among levels. Primary producers commonly exhibit a trade-off between growth rate and competitive ability, such that early successional species that colonize and rapidly grow in open patches are displaced by competitively superior but slow-growing late successional species (Sousa 1979, Grime 2001, Rees et al. 2001). The generality of this trade-off suggests that yield of a plant species in monoculture may often be unrelated, or negatively related, to its competitive ability. This was indeed true of the algal assemblages we studied (Bruno et al. 2005). Additionally, positive interactions can generate higher complementarity (i.e., higher TIC) if the positive interactions occur independently of species traits (here, monoculture yield). In the algal assemblages we studied, positive interactions can occur due to associational defenses (Hay 1986) and amelioration of stress (Allison 2004); neither of these interactions depend on monoculture yield. This combination of life history tradeoffs and positive interactions among primary producers is consistent with mixtures favoring species with lower, rather than higher, monoculture yields (Bruno et al. 2005, 2006). The prevalence among terrestrial plants of similar life history trade-offs (Grime 2001, Rees et al. 2001), positive interactions (Callaway 1995, Tilman et al. 2001, Callaway et al. 2002), frequently weak richness effects on production (Hooper and Dukes 2004), and frequently negative selection effects (Loreau and Hector 2001, Hooper and Dukes 2004, Fox 2005) all suggest that the trade-off mode of interaction we document in macroalgae may be a common phenomenon among terrestrial primary producers as well. If so, these results directly oppose the influential suggestion that traits (here, yield in monoculture) of dominant species overwhelm effects of diversity on primary production (Huston 1997, Aarssen 2003).

In contrast to results for primary producers, our partitioning of the net biodiversity effects suggests that biomass yield of experimental herbivore assemblages was determined by dominant species. The disproportionate yield of dominant herbivore species at the expense of subordinates generated an interaction signature resembling that of simulated dominant communities. One of the grazers (Idotea baltica) used in this experiment could also consume the smaller offspring of other herbivores. Thus, the pattern we observed could have resulted from both competition and intra-guild predation, since a similar signature of dominance would be produced if dominant consumer species were also effective intraguild predators. Intraguild predation represents a qualitatively different mechanism of interaction than occurs in plant assemblages, and potentially explains why interaction signatures differed so dramatically among trophic levels. However, intraguild predation can also allow a weaker competitor to persist when it could not otherwise do so (Holt and Polis 1997). If this occurs, intraguild predation may actually weaken rather than strengthen DE.
A major frontier in understanding biodiversity effects on ecosystem functioning involves extending previous results based on competitive plant assemblages to more complex multitrophic communities (Loreau et al. 2001, Duffy 2002, Thebault and Loreau 2003, Fox 2004a, Bruno and O'Connor 2005, de Ruiter et al. 2005, Gamfeldt et al. 2005, Hooper et al. 2005, Ives et al. 2005). As studies of biodiversity effects on ecosystem functioning expand to consider more complete food webs, the prohibitive logistics of experiments in such complex systems are likely to direct attention increasingly to simulation modeling (Ebenman et al. 2004, Fox 2004b, de Ruiter et al. 2005). Parameterizing such models will require knowledge of the mechanisms by which species interact at different trophic levels. In this study, it appears that the assemblage of primary producers interacts in a fundamentally different way than the assemblage of herbivores, and that these interactions leave clear signatures in their influence on production. The contrasting mechanisms of interaction may ultimately determine how diversity influences ecosystem functioning, and thus how functioning responds to species loss, at different trophic levels. For instance, in this system, the loss of individual primary producer species has little effect on primary production (Bruno et al. 2005). However, the impact of declining herbivore diversity on herbivore yield will depend strongly on the identity of the herbivore lost, with the loss of a dominant herbivore disproportionately more important than the loss of a subordinate herbivore (Duffy et al. 2001, 2003). We suggest that effective conservation and restoration of complex natural food webs should incorporate these differences.

\section{ACKNOWLEDGMENTS}

This research was funded in part by the National Science Foundation (OCE 00-99226 and OCE 03-52343 to J. E. Duffy. and OCE0326983 and OCE0327191 to J. F. Bruno), the University of North Carolina at Chapel Hill, the Institute of Marine Science, and the Virginia Institute of Marine Science. We thank J. Kertesz, A. Long, O. Petchey, two anonymous reviewers, and especially Jeremy Fox for comments.

Literature Cited

Aarssen, L. W. 2003. Is the productivity of vegetation plots higher or lower when there are more species? Variable predictions from interaction of the "sampling effect" and "competitive dominance effect" on the habitat templet. Oikos 102:427-433.

Allison, G. 2004. The influence of species diversity and stress intensity on community resistance and resilience. Ecological Monographs 74:117-134.

Bell, T., J. A. Newman, B. W. Silverman, S. L. Turner, and A. K. Lilley. 2005. The contribution of species richness and composition to bacterial services. Nature 436:1157-1160.

Bruno, J. F., K. E. Boyer, J. E. Duffy, S. C. Lee, and J. S. Kertesz. 2005. Effects of macroalgal species identity and richness on primary production in benthic marine communities. Ecology Letters 8:1165-1174.

Bruno, J. F., S. C. Lee, J. S. Kertesz, R. C. Carpenter, Z. T. Long, and J. E. Duffy. 2006. Partitioning the effects of algal species identity and richness on benthic marine primary production. Oikos 115:170-178. 
Bruno, J. F., and M. I. O'Connor. 2005. Cascading effects of predator diversity and omnivory in a marine food web. Ecology Letters 8:1048-1056.

Byrnes, J. E., J. J. Stachowicz, K. M. Hultgren, A. R. Hughes, S. V. Olyarnik, and C. S. Thornber. 2006. Predator diversity strengthens trophic cascades in kelp forests by modifying herbivore behavior. Ecology Letters 9:61-71.

Callaway, R. M. 1995. Positive interactions among plants. Botanical Review 61:306-349.

Callaway, R. M., et al. 2002. Positive interactions among alpine plants increase with stress. Nature 417:844-848.

Cardinale, B. J., C. T. Harvey, K. Gross, and A. R. Ives. 2003. Biodiversity and biocontrol: emergent impacts of a multienemy assemblage on pest suppression and crop yield in an agroecosystem. Ecology Letters 6:857-865.

Cardinale, B. J., D. S. Srivastava, J. E. Duffy, J. D. Wright, A. L. Downing, M. Sankaran, and C. Jouseau. 2006. Effects of biodiversity on the functioning of trophic groups and ecosystems. Nature 443:989-992.

de Ruiter, P. C., V. Wolters, and J. C. Moore. 2005. Dynamic food webs: multispecies assemblages, ecosystem development and environmental change. Elsevier, Amsterdam, The Netherlands.

Downing, A. L. 2005. Relative effects of species composition and richness on ecosystem properties in ponds. Ecology 86: 701-715.

Downing, A. L., and M. A. Leibold. 2002. Ecosystem consequences of species richness and composition in pond food webs. Nature 416:837-841.

Duffy, J. E. 2002. Biodiversity and ecosystem function: the consumer connection. Oikos 99:201-219.

Duffy, J. E. 2003. Biodiversity loss, trophic skew and ecosystem functioning. Ecology Letters 6:680-687.

Duffy, J. E., K. S. Macdonald, J. M. Rhode, and J. D. Parker. 2001. Grazer diversity, functional redundancy, and productivity in seagrass beds: an experimental test. Ecology 82: $2417-2434$

Duffy, J. E., J. P. Richardson, and E. A. Canuel. 2003. Grazer diversity effects on ecosystem functioning in seagrass beds. Ecology Letters 6:637-645.

Duffy, J. E., J. P. Richardson, and K. E. France. 2005. Ecosystem consequences of diversity depend on food chain length in estuarine vegetation. Ecology Letters 8:301-309.

Ebenman, B., R. Law, and C. Borrvall. 2004. Community viability analysis: the response of ecological communities to species loss. Ecology 85:2591-2600.

Finke, D. L., and R. F. Denno. 2004. Predator diversity dampens trophic cascades. Nature 429:407-410.

Fox, J. W. 2004a. Effects of algal and herbivore diversity on the partitioning of biomass within and among trophic levels. Ecology 85:549-559.

Fox, J. W. 2004b. Modelling the joint effects of predator and prey diversity on total prey biomass. Journal of Animal Ecology 73:88-96.

Fox, J. W. 2005. Interpreting the "selection effect" of biodiversity on ecosystem function. Ecology Letters 8:846856.

Fridley, J. D. 2001. The influence of species diversity on ecosystem productivity: how, where, and why? Oikos 93:514526.

Fukami, T., S. Naeem, and D. A. Wardle. 2001. On similarity among local communities in biodiversity experiments. Oikos 95:340-348.
Gamfeldt, L., H. Hillebrand, and P. R. Jonsson. 2005. Species richness changes across two trophic levels simultaneously affect prey and consumer biomass. Ecology Letters 8:696703.

Grime, J. P. 2001. Plant strategies, vegetation processes and ecosystem properties. John Wiley and Sons, Chichester, UK. Hay, M. E. 1986. Associational plant defenses and the maintenance of species-diversity - turning competitors into accomplices. American Naturalist 128:617-641.

Holt, R. D., and G. A. Polis. 1997. A theoretical framework for intraguild predation. American Naturalist 149:745-764.

Hooper, D. U., et al. 2005. Effects of biodiversity on ecosystem functioning: a consensus of current knowledge. Ecological Monographs 75:3-35.

Hooper, D. U., and J. S. Dukes. 2004. Overyielding among plant functional groups in a long-term experiment. Ecology Letters 7:95-105.

Huston, M. A. 1997. Hidden treatments in ecological experiments: re-evaluating the ecosystem function of biodiversity. Oecologia 110:449-460.

Ives, A. R., B. J. Cardinale, and W. E. Snyder. 2005. A synthesis of subdisciplines: predator-prey interactions, and biodiversity and ecosystem functioning. Ecology Letters 8: 102-116.

Loreau, M., and A. Hector. 2001. Partitioning selection and complementarity in biodiversity experiments. Nature $412: 72$ 76.

Loreau, M., et al. 2001. Ecology, biodiversity and ecosystem functioning: current knowledge and future challenges. Science 294:804-808.

Murrell, D. J., and R. Law. 2003. Heteromyopia and the spatial coexistence of similar competitors. Ecology Letters 6:48-59.

Naeem, S., L. J. Thompson, S. P. Lawler, J. H. Lawton, and R. M. Woodfin. 1994. Declining biodiversity can alter the performance of ecosystems. Nature 368:734-737.

Norberg, J. 2000. Resource-niche complementarity and autotrophic compensation determines ecosystem-level responses to increased cladoceran species richness. Oecologia 122:264272.

Petchey, O. L., A. L. Downing, G. G. Mittlebach, L. Persson, C. F. Steiner, P. H. Warren, and G. Woodward. 2004. Species loss and the structure and functioning of multitrophic aquatic systems. Oikos 104:467-478.

Rees, M., R. Condit, M. Crawley, S. Pacala, and D. Tilman. 2001. Long-term studies of vegetation dynamics. Science 293: 650-655.

Sousa, W. P. 1979. Experimental investigation of disturbance and ecological succession in a rocky intertidal algal community. Ecological Monographs 49:227-254.

Thebault, E., and M. Loreau. 2003. Food-web constraints on biodiversity-ecosystem functioning relationships. Proceedings of the National Academy of Sciences (USA) 100:1494914954.

Thebault, E., and M. Loreau. 2006. The relationship between biodiversity and ecosystem functioning in food webs. Ecological Research 21:17-25.

Tilman, D., P. B. Reich, J. Knops, D. Wedin, T. Mielke, and C. Lehman. 2001. Diversity and productivity in a long-term grassland experiment. Science 294:843-845.

Wardle, D. A., and O. Zackrisson. 2005. Effects of species and functional group loss on island ecosystem properties. Nature 435:806-810. 